\title{
Women's decisions to seek evaluation of self discovered breast symptoms occurred in a complex social context
}

Facione NC, Giancarlo CA. Narratives of breast symptom discovery and cancer diagnosis: psychologic risk for advanced cancer at diagnosis. Cancer Nurs 1998 Dec;21:430-40.

\section{Question}

How do women decide whether and when to seek medical evaluation of self discovered breast symptoms?

\section{Design}

Analysis of narratives generated from 16 focus groups.

\section{Setting}

San Francisco, California, USA.

\section{Participants}

80 women aged $\geqslant 21$ years who were recruited through community organisations, women's groups, churches, and senior centres.

\section{Methods}

Focus groups (6 groups of black women, 4 groups of white women, and 6 groups of Latino women) were held in homes and community meeting rooms and lasted 90-120 minutes. Women were asked what it would be like to discover a problem in their breast, what they thought they would do, and to relate the experiences of women in their families or communities. Sessions were audiotaped, data were transcribed, and narratives were independently analysed by 3 researchers.

\section{Main findings}

Women related 104 narratives of personal experiences with self discovered breast symptoms, as well as those of friends and family. They gave vivid descriptions of the place and time of symptom discovery and understood that the passage of time without treatment added to the threat of the symptom. Some disclosed the symptom to partners or friends, which led to prompt, self initiated visits to a healthcare provider; others failed to disclose the discovery until their disease was advanced. Some women had difficulty interpreting the threat of the symptom and delayed evaluation. Some refused to give the symptom importance, and some blocked it from conscious awareness. Some avoided the term cancer, referring instead to "the big C"; some thought that by avoiding the term, they could exert power over the cancer; and others thought that talking about cancer would cause women to get it.

Women generally endorsed alternative therapies, often in conjunction with traditional medical treatments. Views on the role of God and spirituality varied, but none spoke of religious beliefs that prohibited evaluation or treatment of symptoms. Those who decided not to lose the breast through surgery were seen by some as making a breast conserving choice, by others as experiencing drastic repercussions, and by others as sparing the woman a loss of her femininity. Feelings about symptom discovery included fear of cancer and its treatment and guilt at not discovering symptoms earlier. Experiences with the provider visit included embarrassment during the physical examination, annoyance with the discomfort of the examination, and insensitive or rushed providers. Some women delayed or refused treatment because they feared abandonment by male partners. In some instances, male partners actually obstructed diagnosis or treatment. Poverty inhibited decisions to seek evaluation of symptoms because financial resources were needed for other family problems.

\section{Conclusion}

Women's stories revealed several factors that delayed breast cancer diagnosis: unwillingness to disclose symptoms, incorrect interpretation of the threat of symptoms, a decision not to undergo surgery, embarrassment related to physical examination, fear of abandonment by male partners, and poverty.

Sources of funding: California Breast Cancer Research Program;National American Cancer Society; Sigma Theta Tau Alpha Eta Chapter.

For correspondence:Dr Noreen C Facione, Box 0610, School of Nursing, University of California, San Francisco, CA 94143-0610, USA. Fax +1 4154768899 .

\section{Commentary}

This study by Facione and Giancarlo provides important insights into the psychological risk factors for women's delay in seeking evaluation of breast symptoms. Although breast cancer detection practices have been studied, ${ }^{12}$ issues surrounding decision making after discovering a potentially cancerous symptom have not been well examined. The findings of this study support and expand upon previous research about factors that delay seeking treatment. ${ }^{3}$

Two strengths of the study are the inclusion of 3 ethnocultural groups and the large number of participants. Although the authors avoided recruiting from healthcare agencies, they acknowledge that volunteers may have been motivated by particular concerns about breast cancer.
Only $42 \%$ of the narratives, however, were about personal symptoms, and only $6 \%$ of participants were breast cancer survivors. Althought narrative analysis legitimises the use of secondhand narratives, it would be important to extend this work to women with breast cancer. The focus group format may have led to recruitment of women who were more social than most. Also, some of the economic issues identified in this study might not apply in countries with universal health care. Because the study shows the power of anticipated rejection by a male partner, research is needed into male partners' views and their influence on whether women seek attention for a breast symptom. Other research suggested by these findings includes development and testing of interventions to improve infor- mation about early detection and to effectively support earlier decisions for treatment.

This study gives compelling insights about the complexity of decision making about breast symptoms. It sends a message that failure to act cannot be reduced simply to "ignorance requiring (better) education."

Carolyn Ingram, RN, CON(C), MSc(N) Assistant Professor, School of Nursing McMaster University Hamilton, Ontario, Canada

1 Burnett CB, Steakley CS, Tefft MC. Oncol Nurs Forum 1995;22:1551-8.

2 Choudhry UK, Srivastava R, Fitch MI. Oncol Nurs Forum 1998;25:1693-1701.

3 Guidry JJ, Greisinger A, Aday LA, et al. Oncol Nurs Forum 1996;23:1393-8. 